\title{
Designing Project Management for Global Software Development
} Informality through Formality

\author{
Gitte Tjørnehøj ${ }^{1}$, Maria B. Balogh ${ }^{2}$, Cathrine Iversen ${ }^{2}$, and Stine Sørensen ${ }^{2}$ \\ ${ }^{1}$ Department of Economics, Politics and Public Administration, Aalborg University \\ gtj@dps.aau.dk \\ ${ }^{2}$ Master of Science in Information Technology from Aalborg University Denmark \\ \{mariabbalogh, iversen. cathrine, stiness\}@gmail.com
}

\begin{abstract}
Software development in distributed teams remains challenging despite rapid technical improvement in tools for communication and collaboration across distance. The challenges stem from geographical, temporal and sociocultural distance and manifest themselves in a variety of difficulties in the development projects. This study has identified a range of difficulties described in the literature of global software development, lacking sufficient solutions. In particular, advice for project managers is lacking. Design science research has been applied to design a model to guide project managers of distributed software teams, based on a practice study and informed by well-known theories. Our work pinpoints the difficulties of handling the vital informal processes in distributed collaboration that are so vulnerable because the distances risk detaining their growth and increasing their decay rate. The research suggest to support and securing these informal processes through explicit and formal means and to ensure management's continuous focus on this effort to succeed.
\end{abstract}

Keywords: Global Software Development, Project Management, Informal Processes, Formal Processes, Distributed Teams, Communication, Coordination, Control, Trust.

\section{Introduction}

Global software development (GSD) remains challenging despite rapid technical improvement in media and tools for collaboration over distance [1, 2]. Numerous studies report difficulties when distributing software development across geographical, temporal and sociocultural distances [3]. The challenges manifest themselves in a variety of difficulties on all collaborating levels of the involved organizations. This paper, however, focuses on the level of distributed development projects and thus on the special challenges for the project manager of geographically (and often also temporally and socioculturally) distributed teams.

The literature describes many challenges for GSD projects (see section 2) and also some advice on how to handle these challenges. The common project management 
literature, however, provides little advice for project managers on distributed projects. Project managers can find advice in parallel fields, for example on managing cultural differences in organizations [4,5], managing and building teams (both virtual [6] and co-located [7]), and knowledge management [8]. However, the integration and adaption of this knowledge in(to) the practice of project managers of GSD teams is less widely explored.

This research aims to develop knowledge on how these project managers can cope with the numerous, complex and interwoven challenges that are dominant in their practice. To focus the paper we will present our findings in order to answer the following research question: How do project managers cope with the challenges of GSD, and in particular, how do they establish and sustain the crucial informal processes and interactions in their projects?

We have applied design science to develop a model for distributed global project management. Through the design work we have extracted challenges and design criteria that should apply to the development of models for this purpose. Here we present the most important generic design elements of the proposed solution. We end up suggesting that continuously supporting and securing the informal processes of the distributed team through explicit and formal means is crucial for project success.

The paper is structured as follows. In section 2, GSD challenges are presented and in section 3 the design science approach is described. In section 4 design criteria are formulated and in section 5 the proposed model is sketched and the design elements are described. Section 6 discusses how informality can be supported by formality and section 7 concludes by answering the research question and suggesting further research.

\section{Challenges of Global Software Development Projects}

The rapid technical improvement in media and tools for communication and collaboration over distance ease some of the early reported problems in GSD, but not all [1]. In this overview we have thus focused on described problems that are less likely to diminish through technical means. The challenges of GSD tend to congregate around the processes of communication, coordination and control [3] in projects. Communication is a key issue for GSD. Being dislocated influences all three processes directly, but insufficient and low-quality communication in turn influences control and coordination negatively since good communication and thus good working relations are cornerstones for these two processes [9]. We here present the most commonly reported challenges for GSD in these processes.

The basic problems in communication across distances include language problems and misunderstandings [10], less or no overlap in working hours hindering communication [3], [9], lack of natural communication channels [11] despite the technological progress, fewer or no face-to-face meetings due to the travel costs [3], [12], and delay of communication feedback and increased risk of misunderstandings on the often utilized asynchronous channels [3], [13]. All this makes all communication more demanding for the participants [14] and thus leads to less communication [15] and 
especially less informal communication [16,17]. If (when) sociocultural differences between the on- and offshore organizations exist, the lack of communication (and face-to-face meetings) will hinder the development of personal relations [12], [18], shared knowledge [10], [19,20] and common practice [21] that could have helped overcome the problems. Likewise, the development of mutual understanding and common working culture [9,10], [15], [22] that could have eased difficulties such as misunderstandings [3], conflicts [3] and lack of trust [21], [23] stalls. All in all, the personal relations between team members are weaker than when the team is co-located [24].

Coordinating the work in a project involves both formal and informal processes. The formal processes are often supported by various tools that provide needed insight into products and processes. Distance demands much from these technical tools, which often lack the needed functionality and are often less accessible for offshore employees [3], [25]. For the formal coordination processes to be effective and efficient, informal processes based on substantial shared knowledge, "team awareness" and trust are needed. However, all of these are likely to be weaker or even missing when team members are geographically dispersed because of less and maybe even low-quality communication [3], [14,15,16], [26]. The special challenges of GSD often relate to establishing these fragile informal processes, which is overly difficult when the team is dislocated [27].

Controlling is obviously more difficult when project managers are not located with the entire team. It is difficult to have enough insights into the work of the other location(s) to ensure adherence to goals, policies, standards or quality level [3]. Even the more technical task of configuration and version management of artifacts can be difficult across time zones when based on time stamps. When team members do not share working culture, differences in, for example, understanding of the state of completion of work artifacts [28] and procedures can complicate or even prohibit control. The control process can also be hampered by sociocultural differences in the perception of authority and organizational hierarchies [3], [21]. Kirsch [29] suggests supplementing formal control with an informal control mechanism in complex development work, but the connectedness, shared work culture and social relations it takes for the team to exercise informal control are difficult to build when working in distributed teams [9].

To meet these challenges many different approaches are suggested, from tactics to avoid [9] and reduce the distances [30] to suggestions for tools [31] and methods (for example agile methods [32,33]). Many of these suggestions are useful but often they target only one or a few specific challenges and do not address how mangers of GSD can cope with the complex of interwoven numerous challenges that they face in their everyday work.

\section{Research Approach}

In order to provide help for project managers to face the challenges of GSD projects the research was designed and took place in accordance with Hevner et al.'s [34] model for design science research. The research process is depicted in figure 1 below. 
First the problem area (environment) was investigated in order to grasp and understand more deeply the challenges that practitioners face and ensure the relevance of the research. The exemplary practice was one middle-sized organization in the financial sector with experiences of from 5 to 10 years of offshoring. Six semi-structured interviews with four project managers from three different departments, one project member and one system manager were conducted. The interviews were guided by a literature review on the challenges of GSD that congregates around communication, coordination and control. Most interviews were transcribed and citations from all interviews were organized in data displays structured by the framework of Ågerfalk et al. [3] to support the elucidation of challenges experienced in practice and criteria that could guide the design. Their main challenges were generally found to be in accordance with the theoretically described challenges.

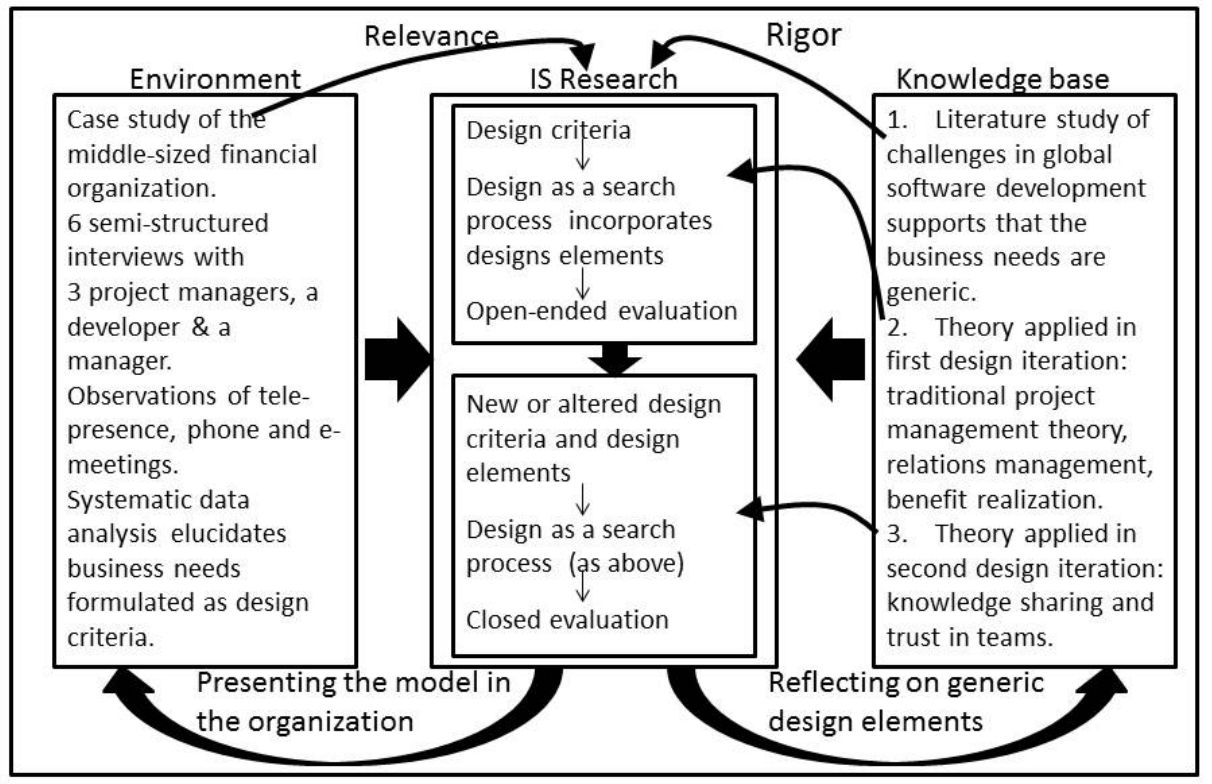

Fig. 1. The design science research process following Hevner et al.'s model [34]

The design criteria (see section 4) were compiled to guide the following two design and evaluation iterations, each resembling the design process described in Hevner \& Chatterjee [35] including problem definition, searching for solutions supported by existing knowledge, artifact development and evaluation that feed new knowledge into the next iteration. Rigor was instilled by taking outset in the knowledge base and by the formulation of generic design elements based on the concrete design.

In practice, the researchers in each design iteration listed the design criteria and the challenges from both practice and literature that lurked behind them and carried out a creative process fluctuating between digging deeper into the problems, searching for theoretical input and coming up with new solution suggestions that they could 
incorporate into the model under design. Activities included literature search and study and available innovative techniques or tools such as mappings, brainstorming, boards, stories etc.

Since evaluation is a significant issue in design science research [36], evaluation strategies in the two iterations were chosen carefully. The model draft resulting from the first iteration was evaluated through open-ended interviews with employees not unlike prototype sessions. The aim was to confirm (or not) the incorporated design elements, but also to gather new ideas for the further development of the model. By opening up for inputs of all kinds including new problems and solutions the practice relevance of the model was enhanced. Figure 2 left shows the visual result from one of those sessions that were also documented through notes and recordings. The confirmations, rejections, comments and new ideas from all the sessions were systematically analyzed and synthesized into new or altered design criteria and design elements (see figure 2 right).

Including the conclusions from the first iteration a second design iteration was carried out. The evaluation of the second model draft and the incorporated design elements were aimed at "testing" the model through an ex ante evaluation. Time constraints limited the effort to an artificial evaluation based on realistic scenarios [36]. The participants (the same as in the first iteration) were asked to evaluate the model using one of their current projects as the test scenario. Again all feedback was synthesized into new or altered design elements, based on which the resulting model for distributed global project management was designed (presented in section 5). Later the model was presented and discussed at a project manager experience meeting in the case organization, where it sparked an interest in and a discussion about how to establish and sustain the informal processes of a globally distributed software development project. This discussion inspired the focus of this paper.

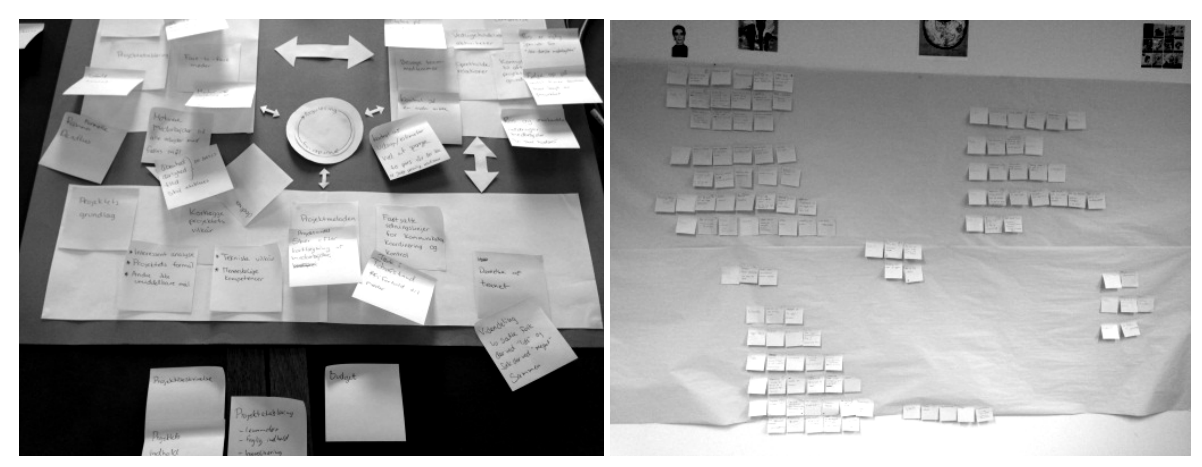

Fig. 2. Left: The visual result from one of the first iteration evaluation sessions. Right: The working area (a board full of post-its) used in the systematic analysis of the results from evaluation during the first design iteration.

Based on the model and its concrete design elements, generic design elements have been formulated trying to pinpoint the learnings from the design work. The most 
important result of this design science research effort is thus the elucidated design criteria and the generic design elements expressing the challenges of globally distributed software development projects and their possible management solutions, while the model in itself has not proven its value in practice - yet.

Another interesting insight is how this design science research process enabled the development of deeper knowledge about the actual practice than an ordinary case study could. Through participating in the iterative design process the practitioners pushed their understanding of their own practice and of possible solutions, and thus provided increasingly deeper insights from the environment. So even though the most important result is the researchers reflections on design criteria and elements, the process also offers an opportunity for the involved organizations to reflect on their own practice and its possible improvements. This effect is not unlike the effect of action research.

\section{The Design Criteria}

\subsection{The Concrete Challenges of the Case Organization}

The investments in outsourcing (time and money) by the case company were beginning to pay back. They had found a fundamentally useful and efficient practice across the global distance, but still saw great possibilities for improvements and their reporting is thus not only beginners struggling. The firm has more domestic development sites and the global practices vary both across these locations and across the different business domains and projects, but all felt a need to improve the management of the projects. The horror stories of cultural misunderstandings, nondelivery and hostile or unwilling attitudes both on- and offshore, so well-known from the literature, were absent in the data, even though many of the known difficulties were enduring.

First, they often experienced obstacles from communicating too little, from being unfamiliar with each other and from unclear expectations across the distances. In addition there were some language problems.

"The geographical distance means that when you work, informal communication is limited. To me the geographical distance is the key challenge." (Project manager)

However, the obvious (and much wanted) solution of more face-to-face meetings through traveling was not economically possible and tele-presence or video conference facilities were also a scarce resource. The project managers spent much time booking the resources needed, underpinning the need to "get closer" in these distributed teams.

Second, bothersome technical problems especially offshore still hindered coordination. Also the important team awareness forming the basis of efficient and effective coordination was feeble because insufficient communication gave weak insights into available skills, the business and the work tasks. 
"it is the classic one when not knowing each other that well; if you give a task to an offshore developer and you do explain it and ask: 'Can you do this task?' the answer is 'yes, I can.' If you give it to an onshore developer they say 'yes, but I'll do it this way and not do this and that and so on...' So I'll get a complete picture of how it will be done, so that I know I can expect it to be done within the scope we agree on and on schedule." (Project manager)

The adoption of agile approaches had in some projects alleviated the problems somewhat, by imposing formal structures to the division of work and coordination of responsibilities, task progress, and task-related knowledge sharing. Still project managers found it challenging to support the necessary informal communication and achieve the necessary personal relations and trust in their teams for dealing with unforeseen situations not accounted for in the formal structures.

"I am not sure if you have heard that we work in agile, where there is nobody who is asking you or ordering you. So the tasks are there, and we have what is known as a rational tool, which we share during the e-meeting where everybody can see that same screen. So when there is a task that is not taken by anybody we just take it. And that is how we share the work. And if I take up a task which I don't know and I would like to learn, then I would take it up and speak to somebody who knows it. Either call them up, or chat with them, send them an email. That's how we pretty much do it." (Developer)

Third, some project managers felt a need for closer control of the performances of their offshore team members.

"But, ehm - it may be something cultural, but the offshore developers tend to need a bit more strict control and firmer management than the onshore developers, because if not you do not know what will be delivered." (Project manager)

All in all, the formal means for control were in place except for a few problems with different perceptions of hierarchy and commitment. However, the projects lacked the informal communications needed to take advantage of the strength of informal control between the members of the teams.

"Informal communication is much easier when you have met face to face, just as it is much easier to trust people you have met." (Project manager)

Most of the challenges described in the literature were present in the organization - or had been present. The organization had, during their first years in offshoring, managed to find solutions for some of the challenges, at least in some of the most advanced projects. Three solutions that the interviewees pointed to were the use of agile methods, their high-tech tele-presence rooms and the visiting training program for offshore employees. These solutions were allowed to inspire the design work. 


\subsection{Five Design Criteria}

Based on the challenges found in the data and described in the literature, five design criteria that are presented here were elucidated.

To communicate within, coordinate and control projects in order to succeed, both formal and informal processes are important [16], [29], [37]. Most project management literature suggests formality in order to secure control and coordination in projects. In the case organization agile approaches provided structure and formality to both coordination and control, but still it was difficult to establish and sustain sufficiently supporting informal processes. The project managers dealing with the distributed teams all found their projects short of team awareness, mutual and affective trust [6], shared working practices, good and adequate communication and knowledge sharing, probably due to the limited face-to-face meetings. Also Gupta and Govindarajan emphasize the importance of informal processes and interaction: "having the right organizational structure but inappropriate informal processes and behavior is more problematic than having an inappropriate organizational structure but the right informal processes and behavior" [38]. Thus the first design criteria for the model for distributed global project management focus on informal processes as the key component.

1. It is important that the model can support project managers in establishing informal processes and interactions within GSD project teams.

Good communication is the foundation for effective informal processes as well as for informal coordination and control. In the case organization, managers felt unsure whether the informal control worked across distance in their projects and they experienced coordination problems that would be handled informally if co-located.

2. Thus the model needs to support informal processes and interactions for coordination and control, but most importantly for communication as successful communication provides a necessary basis for the others.

Relations will develop in any collaboration through the interactions that take place. Poor interactions risk resulting in poor relations and can turn into mistrust, hostility and withdrawal. Redressing bad relations and mistrust is very hard, so establishing a good trusting relationship from the start and sustaining it actively and continuously is crucial [6]. Distance gives rise to many misunderstandings that can even be difficult to realize, so good relations are under pressure throughout the project.

3. Any such model should emphasize the sustainment of the trust and personal relations needed for continued successful informal processes and interactions.

In the case organization, formal processes as described in traditional project management literature formed the backbone of the projects. Many authors recommend these tools and methods while stressing that these are not sufficient and may not even be addressing the biggest challenges [39]. To be successful, both formal and informal processes are needed [16]. 
4. While accentuating the informality above, the model needs to embrace the formal processes and interactions that are so well described in the literature already to allow project managers to integrate formal and informal processes into an effective and efficient management practice.

The above criteria are at a rather abstract level of description. From the interviews it was clear that project managers needed both this kind of deeper understanding of their complex challenges and concrete advice that they could integrate and test in their own practice. They were looking for more tools to add to their already existing toolbox. In particular, explicit and concrete models would be very helpful for new project managers or project managers new to GSD projects.

5. Such a model must both support understanding of the complex practice of managing GSD projects and provide concrete advice that (new) managers can utilize.

These abstract design criteria were elucidated from the challenges of GSD described in the literature and the empirical findings. They express the priority and focus that, it is argued, any tool for GSD project management should have, though the formal processes described in design criterion 4 are well described in more general project management models also used in co-located projects.

\section{$5 \quad$ The Design Elements}

The seven design elements are based on the learning from the concrete design solution. The proposed model is presented in section 5.1 followed by an overview of how the model satisfies the criteria in 5.2. Finally, the design elements are formulated and argued in 5.3.

\subsection{The Proposed Model for Distributed Global Project Management}

The proposed model consists of four focus areas: clarifying project conditions, project establishment, execution of the project (which is repetitive) and post-project evaluation. The focus areas have no resemblance with project phases, but express important concerns for the project manager throughout the project. At any time, change and unexpected events can demand the project manager to refocus between the focus areas. However, clarifying project conditions and project establishment will probably need most management attention initially, while post-project evaluation is likely to take place late in the project.

This model may seem to accentuate the traditional start-up activities of clarifying project conditions and establishing the project in comparison with the actual systems development activities. The scope of the model is activities necessary for handling the special challenges of GSD, while activities that are parallel to the ones in co-located projects have been left out. The focus area of project execution holds the executionintegrated activities sustaining the well-functioning team, while breakdowns often demands project managers to reclarify conditions or re-establish the project. 
The focus area of clarifying project conditions aims to provide a solid foundation for successful GSD project execution. Traditional tasks aimed at understanding the work, goals, risks and stakeholders of the project and grounding the choice of formal structures, organization and methods for the project are carried out, but with special considerations of the challenges of GSD. Project managers should explicitly strive for formal structures that allow for, support or even demand informal processes. An example is the agile approaches that are well-known in the case organizations for demanding and supporting frequent, direct and rather informal contact across the distances between the on- and offshore team members.

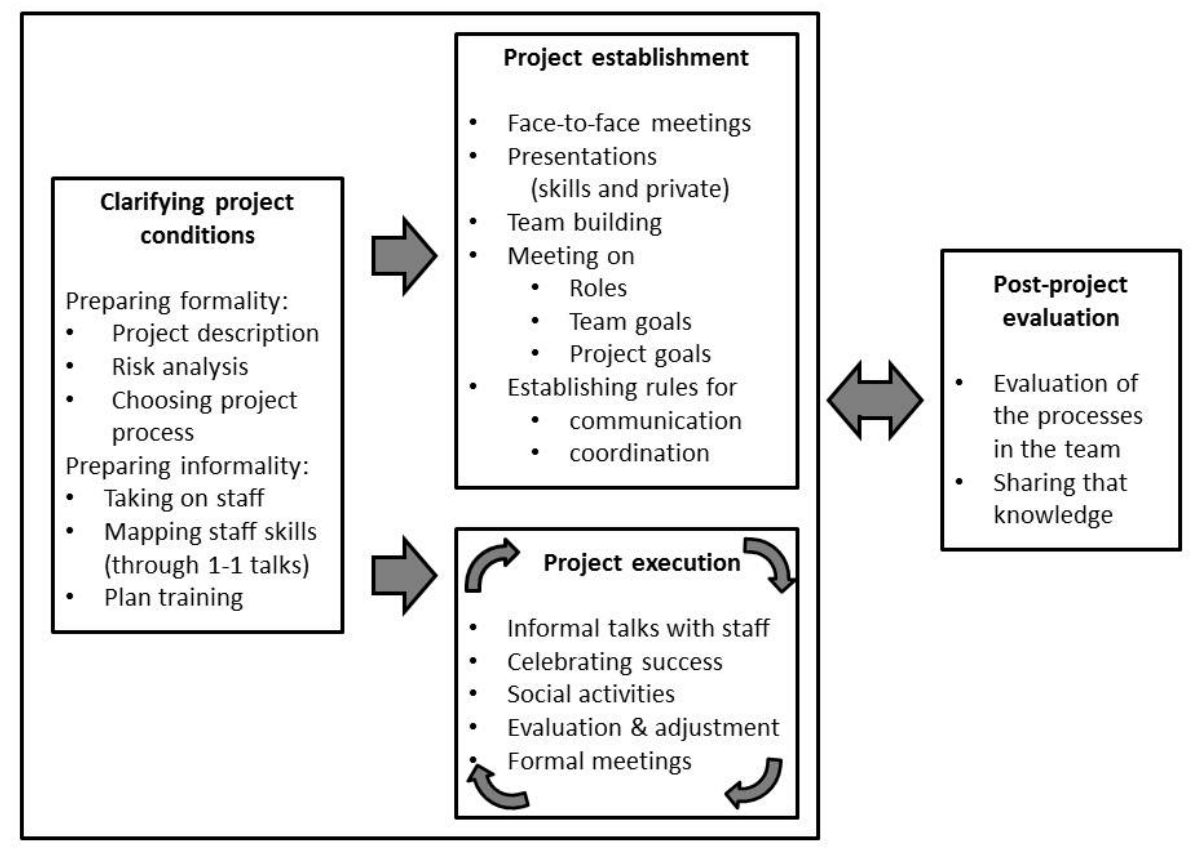

Fig. 3. The four focus areas of the model for distributed global project management. For each focus area recommended activities are listed.

Just as important are activities to create the bedrock for developing trust and good personal relations in the team [1], [13], [24]. The literature confirms that management attention before and during staffing is crucial [6], [27]. Managers need to understand the goals and tasks of the project in order to staff properly, taking into account both professional skills and personal skills in communication, bonding and cross-distance work. They need explicitly to plan for staffing and mapping of skills [40] in order to arrange for necessary pre-project or project-start-up training. Often training on culture, communication and business knowledge is appropriate [13], [26]. The skillmapping is recommended to take place through one-to-one talks between the project 
manager and every team member. Through these conversations the manager can display leadership and start to build a trusting relationship with the team members.

During project establishment the project team should establish themselves as a team, while the project manager provides the needed settings and support. In order to commit themselves, the team members must get to know each other both professionally and personally to build trust and relations and to reach a common understanding on the tasks, goals and working approaches of the project [41]. This is a very complex process and is best done through face-to-face meetings that can involve employees' personal presentations, team-building activities, discussions of roles, team and project goals and establishing norms for communication and coordination tasks in the project [42]. This is the key focus area for establishing the informal processes of the GSD project and is only rarely given enough attention, even in the case organization. Since these kinds of relations, common understandings and agreements are usually renegotiated continuously in co-located projects, the project manager instead must continuously refocus on this area and make sure that the team re-establishes if required.

Sustaining the informal processes is the key goal of the project execution focus area. Also the formal processes need to be sustained, but these are often sustained through the mere systems development and management activities of the organization that are well described in the existing literature, and even though distance does matter for these too, the progress in support tools has reduced the impact. Examples of activities of this focus area that can sustain personal relations, trust and commitment towards the team are informal talks between the project manager and team members, frequent celebrations of successes or other social activities throughout the project and continuous explicit evaluation and adjustment of the agreed-on processes as part of a planned line of formal meetings.

Through the focus area of post-project evaluation, learning at individual, project and organizational level is stressed because knowledge sharing by the case organization was mentioned as being crucial for successful project management in GSD. The project managers must evaluate the activities targeting the needed informal and formal processes to contribute to shared knowledge in the organization. For individual team members the one-to-one talks with the project manager will help to turn experiences into valuable knowledge for the next projects.

\subsection{Satisfying the Design Criteria}

This section provides an overview of how the model design satisfies the design criteria by listing the elements that contribute to the satisfactory solution. For each design criterion the basic assumptions that the design elements rest on is articulated.

Table 1. How the design criteria are satisfied by the model design

\begin{tabular}{|l|l|}
\hline Design criterion 1 & Support establishment of informal processes. \\
\hline Basic assumption & $\begin{array}{l}\text { The foundation for informal processes is the team members' mutual } \\
\text { relations and trust, team awareness and shared work practice and } \\
\text { understandings. }\end{array}$ \\
\hline
\end{tabular}


Table 1. (Continued)

This design criterion is mainly satisfied through the two early focus areas and their activities: - Clarifying project conditions pinpoints a need for preparatory management activities and puts emphasis on staffing, personal skills, pre-project training targeting the GSD challenges and early exercising of leadership and initial trust building.

-The key for Project establishment is to ensure that the team establishes itself as a team, which happens best through face-to-face meetings, team-building activities, and discussions on roles and goals. Norms for communication and coordination must be explicitly agreed on.

\begin{tabular}{|l|l|}
\hline Design criterion 2 & $\begin{array}{l}\text { Ensure informal processes within all of communication, coordination } \\
\text { and control. }\end{array}$ \\
\hline Basic assumption & $\begin{array}{l}\text { Good communication and personal relations and trust are both impor- } \\
\text { tant for and result from informal processes. Good teamness and com- } \\
\text { munication allow for better informal coordination and control. The } \\
\text { opposite hinders informal coordination and control. }\end{array}$ \\
\hline
\end{tabular}

The model provides advice for all these areas:

- The activities of the two early focus areas provide the conditions for close personal relations and trust to develop and thus for informal communication to happen. In particular, the explication of communication norms and the staffing with communication skills and culture awareness in mind is very important.

- Norms for coordination are explicitly discussed and an appropriate choice of systems development approaches that support informal coordination is encouraged. Also continuous exercising, evaluation and adjusting of informal coordination during project execution is important.

-The choice of formal structures, for example an appropriate system development approach, is important to enhance informal control. For example, the agile practice of stand-up meetings and burn down charts provides the basic information for informal control in the project to develop. The team awareness and teamness accomplished in the above-mentioned activities will lay the grounding for informal control within the team.

\begin{tabular}{|l|l|}
\hline Design criterion 3 & Support sustaining of informal processes. \\
\hline Basic assumption & $\begin{array}{l}\text { Since conditions in GSD projects change continuously and distances } \\
\text { continuously create (new) threats towards teamness the informal } \\
\text { processes need to be sustained continuously. }\end{array}$ \\
\hline
\end{tabular}

The concept of focus areas rather than phases mirrors this basic assumption.

The focus area of project execution explicitly designed to sustain the team relations and provide opportunities for team building and re-establishments by integrating activities such as celebrations, evaluations and renegotiations of informal norms and work practices as part of the formal agenda of the project.

The focus area of post-project evaluation enables "sustaining" across projects by knowledge sharing. 
Table 1. (Continued)

\begin{tabular}{|l|l|}
\hline Design criterion 4 & Support establishing of appropriate formal processes. \\
\hline Basic assumption & $\begin{array}{l}\text { The formal processes are the easiest to establish and sustain as they } \\
\text { are visible in procedures and documents and "speak" of projects and } \\
\text { many tools for distributed collaboration focus on these processes. } \\
\text { Thus it is important to establish these and it could be convenient for } \\
\text { informal processes to piggyback on them if possible. }\end{array}$ \\
\hline $\begin{array}{l}\text { The focus area of clarifying project conditions is intertwined with the traditional start-up } \\
\text { activities of understanding the tasks and goals of the project, establishing the formal organi- } \\
\text { zation, and evaluating risks and stakeholder interests. All this provides the basis for the } \\
\text { formal processes of the project. But the attention of the manager is here drawn to choosing } \\
\text { formal processes that can benefit the informal processes. }\end{array}$ \\
\hline Design criterion 5 & Provide concrete advice. \\
\hline Basic assumption & $\begin{array}{l}\text { Each project manager has to adapt his practice all the time as the } \\
\text { professional practitioner [43] he or she is. Concrete and detailed ad- } \\
\text { vice eases the process of integrating new practices into the exciting } \\
\text { practices of these professionals. }\end{array}$ \\
\hline $\begin{array}{l}\text { This criterion was met in the model presented to the organization, but is unfortunately not } \\
\text { reported in these details here. }\end{array}$
\end{tabular}

\subsection{Seven Design Elements}

The learning from the concrete design solution is summarized in seven generic design elements that are important aspects of the solution found important for all project management practices in GSD.

Management models tend to focus on either formal or informal processes, only rarely including both equally in their prescribed solutions. An important design element in this model is that the two are equally important for successful management of GSD projects. Not only are both kinds of processes needed, but the project manager can take advantage of formality in order to strengthen the more vulnerable informal processes so badly affected by distance, if they choose the ordinary formal structures with that in mind, and add formality to traditionally purely informal processes. This gives rise to the following three design elements:

1. Include both formal and informal processes.

2. Choose formal structures conscious of the need for informal processes.

3. Formalize informality.

The team, their relations and commitment are, as described clearly above, the key for informal processes to contribute to successful GSD projects. So explicit activities to establish and sustain the team and their teamness are an important design element.

\section{Explicit activities to establish and sustain the team.}

The role and timing of project management are also important for the solution suggested here. First it is important to display leadership early in order to increase the likelihood of trust building and commitment in the team. Getting a good start is not enough. This model suggests the elements of focus areas in opposition to phases, to 
underpin the constant need for monitoring and adjusting with respect to the informal and formal processes throughout the life span of the project.

6. Early leadership through staffing and considerate planning.

7. Focus areas, not phases, are needed.

Eventually knowledge sharing between projects over time will help project managers to adapt their practice to the ever-changing conditions.

8. Learning from the past will ease the future projects.

In this paper the design elements of the relationship between formal and informal processes are regarded as the most important results, and how project managers by combining them wisely can take full advantage of both is reckoned to be an important discussion.

\section{Discussion}

The core of distributed work is the dislocation [30], although other distances are mentioned as providing equal challenges. Even if successful in diminishing sociocultural and temporal distance, the dislocation will still naturally lower the interaction between team members [2]. The negative effects start occurring when workplace distance is more than 30 meters [37], [44], thus being an inherent challenge for project managers of GSD.

For newcomers to offshoring, establishing the necessary formal processes will probably be the first challenge, but since these processes are well described in the literature, visible in the organization and the target of many tools for distributed collaboration, they may be relatively easy to establish and sustain. If an appropriate choice of formal processes is in place, they can form the backbone of the collaboration through explicit procedures, formal roles and responsibilities and allow essential information about tasks and progress to flow. However, formal processes tend to be rather static, bureaucratic and conservative, which makes them less suited to complex, fast-changing and unpredictable environments.

In such environments human agency is suitable and informal processes bear the capacity of rapid change, adaptive and improvisational behavior to meet the complex and unexpected. If successful, the informal processes ensure a greater visibility in the project, by allowing for much richer information and knowledge sharing than by only formal means [45]. This broadcast of knowledge and information allows the team members to develop trust and team awareness and thus (re)commit themselves to the task and the team, allowing for effective informal control and coordination. Because of the increased informationflow project managers can realize unexpected situations timely and the robust informal processes let the team rise to the challenges.

These informal processes are just as difficult to establish and sustain in GSD as they are vital. Good personal relations and trust between team members are both the root of and stem from informal processes and interactions. They form a kind of snowball effect that naturally gathers speed when interacting face to face and results in a 
feeling of teamness. However, face-to-face communication only happens rarely in distributed teams because of travel costs; even though to some extent it is substitutable by high-tech tele-presence media, these are still rather costly and thus rare resources. Despite technological development, it is still reported that face-to-face settings do work better for building trust and awareness. So until saved by technology, other means will have to do and the vital informal processes often never develop [2] or diminish quickly.

Personal relations, trust and informal processes will be negotiated continuously, build and decay through experiences in the project. Being distributed, the risk of decay is greater because of more potential misunderstandings and difficulties of settlements due to more effort-demanding communication. At the same time, the building of trust and relationships is not supported through natural settings or structures of the project (as it is in co-located settings). Examples of very important structures in colocated projects are the coffee machine or printer or corridors that allow people to meet informally and discuss and even settle important matters.

This vulnerability of the informal processes incites focused and careful management, employing the more sturdy formal processes as a support and stabilizing the informal processes by introducing and insisting on formality in and around these processes. Examples of this drawn from the proposed model above will be discussed in the following.

Managers can add formality through procedures. Project managers can support their meticulous preparation for project start-up by describing it in project procedures along with, for example, risk assessment or stakeholder analysis. They will carefully have to map the GSD challenges of the project as a backdrop for describing staff requirements, interviewing employees, careful staffing and planning needed training - activities that, if done in close communication, preferably face to face with employees, can spark trust building and commitment. The formality of the actual inquiry and interviews helps provide the needed resources and make room for the activity in crowded calendars. Still the content and the tone of the inquiry and the interviews need to be informal to allow for sufficient information to flow and for trust to start building. This formal "hiring" process provides the best conditions for swift trust between team members from the start, since they know that all have been evaluated and approved [6].

Formality with regard to meetings, in agendas, chairing, preparation and documentation, can support informal meetings by ensuring they actually happen and by allowing the necessary time to be taken. For example, project managers need to support team establishment, even if the full team does not meet in person. It may be difficult to find time to meet for the vital social team-building activities, ${ }^{1}$ but formal notice, agendas and memos for start-up meetings mixing "professional" topics and activities to lay the ground for informal processes will signal the importance and create participation. Participants are more likely to prepare decently for both personal presentations and professional topics such as understanding the task, roles, goals etc. When chairing the establishment events, the project manager should insist on spending enough time "with each other" online (if face to face is not possible) in order to explicitly discuss informal processes as well such as roles and norms for communication and coordination.

\footnotetext{
${ }^{1}$ http: / /www. infiniteams.com/ is an example of an online team-building game.
} 
Whatever is negotiated and decided should be documented semi-formally, for example in a project charter, to stabilize the agreements, but also to allow for easy change.

Exploiting the already installed formal structures is an obvious possibility. Piggybacking on the formal processes of the systems development can be done by adding informal routines to the formal ones For example, tele-presence meetings could start with a coffee together for ten minutes, celebrations of successes could be shared across the distance through appropriate media and the built-in evaluations of the progress can include explicit evaluations (and adjustments) of not only the formal but also the informal processes. This way the project manager can nurse the connectedness of the team and the informal processes throughout the project without special arrangements.

All routines can strengthen the informal processes. For example, the project manager can keep in close contact with the individual team member to ensure that information flows by frequent regular phone calls that allow for informal communication. Because the calls are routine the team member gets the opportunity to air concerns and is likely to speak freely.

Finally, explicit inheritance of practice from well-performed finished projects will ease the establishment of the new projects. This can be done through knowledge sharing, planning for and insisting on post-project evaluations and learning. However, experience shows that post-mortem analysis is likely to fail, so maybe the evaluations could start in the last iterations of the project execution. It may be easier to keep (parts of) successful teams when staffing new projects bringing a practice to start from. Of course, the risk is that old habits and too much teamness will prevent the team from taking on new tasks, including newcomers and improving work approaches. Even though the problem of knowledge sharing is not special for GSD, the investment needed to establish and sustain teams as the basis for the crucial informal processes is higher here, and thus finding a solution is more important.

Through the design work and the reflection presented here it has become evident that the informal processes in GSD project work are crucial yet very difficult to establish and sustain. The described design elements and this discussion suggest that project managers should choose formal processes not only for their own means but also for supporting the establishment and sustaining of informal processes and they should add formality even to processes that do not need formality when the team is co-located. Even if this is done, project management must still monitor and insist on informal processes to sustain an appropriate level of connecting, trusting and sharing knowledge across work locations in distributed teams. All this effort can, of course, fail, just as if the team was co-located. In both cases conflict resolutions, training or even new team members may help, but that is not particular to GSD.

\section{Conclusions}

The research was carried out in order to provide project managers with advice on how to cope with the challenges of GSD. Design science was applied to develop a draft of a project management model that could be helpful. Through the study of the research environment, GSD challenges were mapped and confirmed as generic through literature studies. Five design criteria were formulated to guide the development of project 
management models for this purpose and seven generic design elements were formulated based on the proposed model. Finally, how to support informal processes through formality was discussed, answering the research question by concluding that project managers will cope with the challenges of GSD by:

- Finding a viable balance between formal and informal processes in the project to exploit both the stability, visibility and order of the formal and the flexibility, engagement and agility that the informal provide.

And that they establish and sustain the crucial informal processes by:

- Choosing formal processes conscious of the need for informal processes.

- Supporting informality by formal means as discussed above.

- Investing a great deal of effort early in the project in order to establish the good conditions that eventually can lead to good informal processes.

- Supporting team establishment, creation of personal relations, building of trust and teamness as a foundation for informal processes.

- Explicitly and continuously managing well-functioning informal processes.

- Working towards knowledge sharing across instances of GSD projects.

All in all, the research suggests that supporting and securing the informal processes of the distributed team through explicit and formal means and continuously keeping the foundation for and the informal processes in management's focus are crucial for project success. Project managers are advised to do exactly that, and to find inspiration in the design elements presented above. Organizations that rely on GSD are advised to provide the formal means and allow for the apparently extra work of grounding the informal processes at project initiation and later [41].

However, this research gives only examples of means that could work. Since the proposed model as such has not been evaluated on a full scale, evidence of actual effect is NOT reported here. Testing out the tenet of supporting informality through formality in GSD projects to increase their success rates could be an interesting way forward for future research, where perhaps the ideas from second-order project management [46] could be inspirational.

\section{References}

1. Kotlarsky, J., Oshri, I.: Social Ties, Knowledge Sharing and Successful Collaboration in Globally Distributed System Development Projects. European Journal of Information Systems 14, 37-48 (2005)

2. Sarker, S., Sahay, S.: Implications of Space and Time for Distributed Work: An Interpretive Study of US-Norwegian Systems Development Teams. European Journal of Information Systems 13, 3-20 (2004)

3. Ågerfalk, P., Fitzgerald, B., Holmström, H., Lings, B., Lundell, B., Conchúir, E.: A Framework for Considering Opportunities and Threats in Distributed Software Development. In: Proceedings of the International Workshop on Distributed Software Development, pp. 47-61 (2005) 
4. Hofstede, G.: Culture and Organizations. International Studies of Management \& Organization 10, 15-41 (1980)

5. Schein, E.H.: Organizational Culture and Leadership, 3rd edn. John Wiley and Sons, Inc., San Francisco (2006)

6. Greenberg, P.S., Greenberg, R.H., Antonucci, Y.L.: Creating and Sustaining Trust in Virtual Teams. Business Horizons 50, 325-333 (2007)

7. Wenger, E.: Communities of Practice: Learning, Meaning, and Identity. Cambridge University Press, Cambridge (1998)

8. Sambamurthy, V., Subramani, M.: Special Issue on Information Technologies and Knowledge Management. MIS Quarterly 29, 193-195 (2005)

9. Carmel, E., Agarwal, R.: Tactical Approaches for Alleviating Distance in Global Software Development. IEEE Software 18, 22-29 (2001)

10. Ai, S., Du, R., Abbott, P., Zheng, Y.: Internal and Contextual Factors, Knowledge Processes and Performance: From the Chinese Provider's Perspective. Expert Systems with Applications 39, 4464-4472 (2012)

11. Kock, N.: Compensatory Adaptation to Media Obstacles: An Experimental Study of Process Redesign Dyads. Information Resources Management Journal 18, 41-67 (2005)

12. Šmite, D., Borzovs, J.: A Framework for Overcoming Supplier Related Threats in Global Projects. In: Richardson, I., Runeson, P., Messnarz, R. (eds.) EuroSPI 2006. LNCS, vol. 4257, pp. 50-61. Springer, Heidelberg (2006)

13. Verburg, R.M., Bosch-Sijtsema, P., Vartiainen, M.: Getting it Done: Critical Success Factors for Project Managers in Virtual Work Settings. International Journal of Project Management 31, 68-79 (2013)

14. Daim, T.U., Ha, A., Reutiman, S., Hughes, B., Pathak, U., Bynum, W., Bhatla, A.: Exploring the Communication Breakdown in Global Virtual Teams. International Journal of Project Management 30, 199-212 (2012)

15. Herbsleb, J.D.: Global Software Engineering: The Future of Socio-Technical Coordination. In: Future of Software Engineering (FOSE 2007), pp. 188-198 (2007)

16. Espinosa, J.A., Slaughter, S.A., Kraut, R.E., Herbsleb, J.D.: Team Knowledge and Coordination in Geographically Distributed Software Development. Journal of Management Information Systems 24, 135-169 (2007)

17. García Guzmán, J., Saldaña Ramos, J., Amescua Seco, A., Sanz Esteban, A.: How to Get Mature Global Virtual Teams: A Framework to Improve Team Process Management in Distributed Software Teams. Software Quality Journal 18, 409-435 (2010)

18. Qureshi, S., Liu, M., Vogel, D.: The Effects of Electronic Collaboration in Distributed Project Management. Group Decision and Negotiation 15, 55-75 (2005)

19. David, G.C., Chand, D., Newell, S., Resende-Santos, J.: Integrated Collaboration Across Distributed Sites: The Perils of Process and the Promise of Practice. Journal of Information Technology 23, 44-54 (2008)

20. Kotlarsky, J., van Fenema, P.C., Willcocks, L.P.: Developing a Knowledge-Based Perspective on Coordination: The Case of Global Software Projects. Information \& Management 45, 96-108 (2008)

21. Levina, N., Vaast, E.: Innovating or Doing as Told? Status Differences and Overlapping Boundaries in Offshore Collaboration. MIS Quarterly 32, 307-332 (2008)

22. Kumar, K., van Fenema, P.C., von Glinow, M.A.: Offshoring and the Global Distribution of Work: Implications for Task Interdependence Theory and Practice. Journal of International Business Studies 40, 642-667 (2008)

23. Lanubile, F., Calefato, F., Ebert, C.: Group Awareness in Global Software Engineering. IEEE Software 30, 18-23 (2013) 
24. Lin, C., Standing, C., Liu, Y.: A Model to Develop Effective Virtual Teams. Decision Support Systems 45, 1031-1045 (2008)

25. Tunkelo, T., Hameri, A., Pigneur, Y.: Improving Globally Distributed Software Development and Support Processes - A Workflow View. Journal of Software: Evolution and Process 25, 1305-1324 (2013)

26. Søderberg, A., Krishna, S., Bjørn, P.: Global Software Development: Commitment, Trust and Cultural Sensitivity in Strategic Partnerships. Journal of International Management 19, 347-361 (2013)

27. Pauleen, D.J.: An Inductively Derived Model of Leader-Initiated Relationship Building with Virtual Team Members. Journal of Management Information Systems 20, 227-256 (2003)

28. Sutherland, J., Viktorov, A., Blount, J., Puntikov, N.: Distributed Scrum: Agile Project Management with Outsourced Development Teams. In: HICSS 2007 the 40th Annual Hawaii International Conference on System Sciences, p. 274a (2007)

29. Kirsch, L.S.: Portfolios of Control Modes and IS Project Management. Information Systems Research 8, 215-239 (1997)

30. Carmel, E., Abbott, P.: Why 'Nearshore' Means that Distance Matters. Communications of the ACM 50, 40-46 (2007)

31. Lanubile, F., Ebert, C., Prikladnicki, R., Vizcaino, A.: Collaboration Tools for Global Software Engineering. IEEE Software 27, 52-55 (2010)

32. Holmström, H., Fitzgerald, B., Ågerfalk, P.J., Conchúir, E.Ó.: Agile Practices Reduce Distance in Global Software Development. Information Systems Management 23, 7-18 (2006)

33. Ramesh, B., Cao, L., Mohan, K., Peng, X.U.: Can Distributed Software Development be Agile? Communications of the ACM 49, 41-46 (2006)

34. Hevner, A.R., March, S.T., Park, J., Ram, S.: Design Science in Information Systems Research. MIS QQuarterly 28, 75-105 (2004)

35. Hevner, A., Chatterjee, S.: Design and Creativity. In: Design and Creativity Design Research in Information Systems, pp. 145-156. Springer (2010)

36. Pries-Heje, J., Baskerville, R., Venable, J.R.: Strategies for Design Science Research Evaluation. In: Proceedings of the 16th European Conference on Information Systems, ECIS 2008 (2008)

37. Herbsleb, J.D., Mockus, A.: An Empirical Study of Speed and Communication in Globally Distributed Software Development. IEEE Transactions on Software Engineering 29, 481-494 (2003)

38. Gupta, A.K., Govindarajan, V.: Global Strategy and Organization. John Wiley, Danvers (2004)

39. DeMarco, T.: The Deadline: A Novel AboutProject Management. Dorset House Pub., New York (1997)

40. Whitener, E., Stahl, G.K.: Creating and Building Trust. In: Lane, H.W., Masnevski, M.L., Mendenhall, M.E., et al. (eds.) The Blackwell Handbook of Global Management: A Guide to Managing Complexity, pp. 109-120. Blackwell Publishing Ltd., Oxford (2004)

41. Gluesing, J.C., Gibson, C.B.: Designing and Forming Global Teams. In: Lane, H.W., Masnevski, M.L., Mendenhall, M.E., et al. (eds.) The Blackwell Handbook of Global Management: A Guide to Managing Complexity, pp. 199-226. Blackwell Publishing Ltd., Oxford (2004)

42. Pries-Heje, J., Pries-Heje, L.: Designing Virtual Team Building with a Focus on Social Capital. In: Hertzum, M., Jørgensen, C. (eds.) SourceIT: Balancing Sourcing and Innovation in Information Systems Development, pp. 123-144. TAPIR Akademisk Forlag (2011) 
43. Schön, D.A.: The Reflective Practitioner: How Professionals Think in Action. Basic Books, Inc. (1983)

44. Allen, T.B.: Managing the Flow of Technology: Technology Transfer and the Dissemination of Technological Information within the R\&D Organization. MIT Press, Cambridge (1977)

45. Oshri, I., van Fenema, P.C., Kotlarsky, J.: Knowledge Transfer in Globally Distributed Teams: The Role of Transactive Memory. Information Systems Journal 18, 593-616 (2008)

46. Saynisch, M.: Mastering Complexity and Changes in Projects, Economy, and Society Via Project Management Second Order (PM-2). Project Management Journal 41, 4-20 (2010) 